\title{
Luiz Francisco Rebello e a censura: diálogos com a História ${ }^{1}$
}

\author{
MARIA HELENA SERÔDIO
}

Denouncing and exposing censorship procedures has been one of Luiz Francisco Rebello's (1924-2011) most visible lines of action, whether in his public interventions, his theatrical practice, his playwrighting or in his theatre historiography. In this essay, we remember and discuss some key moments of Rebello's resistance to censorship: his intervention as keynote speaker in the International Federation for Theatre Research (Lisbon, 2009); his controversial direction of the Companhia do Teatro Municipal, performing in the municipal venue Teatro São Luiz (1971); his participation in the organization of a conference cycle on German documentary-theatre (1972); and in the $2^{\text {nd }}$ Republican Congress, where he discussed the situation of theatre in Portugal (Aveiro, 1969). We also look back on his play, Portugal, anos 40, directed by Carlos Avilez (at the Calouste Gulbenkian Foundation, 1982).

LUIZ FRANCISCO REBELLO / CENSORSHIP / ARTISTIC RESISTANCE / PORTUGUESE THEATRE / HISTORY

Em 2009, Luiz Francisco Rebello foi convidado pelo Centro de Estudos de Teatro da Faculdade de Letras da Universidade de Lisboa a proferir a conferência inaugural do Congresso Internacional da FIRT (Fédération Internationale pour la Recherche Théâtrale), que nesse ano o nosso centro se responsabilizara por organizar e que se realizou em Julho. O tema geral escolhido por nós - e aceite com entusiasmo pela direcção da FIRT - tinha sido o da censura ao teatro, abrindo, necessariamente, para outras artes (como o cinema, a dança e a performance), bem como para múltiplas perspectivas teóricas, metodológicas e críticas na análise dessa temática tão abrangente.

Com o título genérico Vozes silenciadas, Vidas proibidas: A censura e o teatro, o congresso ouviu na sessão inaugural a conferência de Luiz

1 Texto originalmente apresentado no Congresso internacional «Censura ao Teatro e ao Cinema», organizado pelo Centro de Investigação Media e Jornalismo (CIMJ), Faculdade de Ciências Sociais e Humanas, a 14 de Novembro de 2013. 
Francisco Rebello - apresentada na Aula Magna da Reitoria - e que tinha por título «Vozes silenciosas, vozes silenciadas»².

Numa visão geral mas expressiva, Rebello dava conta do que tinha sido a actuação da censura através de alguns indicadores - obsessivamente presentes ao longo da História de Portugal - e esclarecia que, no século $\mathrm{xx}$, as motivações centrais obedeciam a «duas linhas de força dominantes [...]: a ideologia política e a moral católica». Se, porventura, não fosse claro para o censor o sentido de algum dos textos, a regra era, e cito ipsis verbis, «reprovar na dúvida e por prudência». À força da sua imposição em tudo quanto se escrevia, publicava, representava ou filmava, a imagem do país que se transmitia, como esclarecia Luiz Francisco Rebello, era:

[...] a de um país em que não havia suicídios, abortos, greves, fome, epidemias, analfabetismo, homossexualidade, consumo de droga, em que as eleições não eram falsificadas, os tribunais não condenavam inocentes, a polícia não torturava nem matava, os soldados não desertavam nem morriam na guerra colonial porque não havia guerra nem colónias nem províncias ultramarinas, e até - supremo paradoxo - não havia censura. (2009: 10)

Por essa razão de circunstâncias e consequências tão «ideais», Rebello considerava que a imagem que se transmitia era que «Portugal não era um país, mas uma sucursal do Paraíso».

Na sua autobiografia, O Passado na Minha Frente, Luiz Francisco Rebello revela cumulativamente o gosto (e a competência) em «fazer História», ao mesmo tempo que leva a convergir no lugar público - da actuação colectiva - episódios que, sendo embora da História do teatro português, o integram como protagonista de factos decisivos para avaliar as condições de «fazer teatro» em Portugal.

Nesse circuito entre a confissão privada e o relato de factos públicos, está um momento importante relativo ao convite que lhe tinha sido dirigido em Maio de 1971 pelo então presidente da Câmara Municipal de Lisboa (engenheiro Santos e Castro) para formar e dirigir a Companhia do Teatro Municipal que actuaria no Teatro São Luiz, adquirido recentemente pela câmara. A evocação de todo esse processo integra um debate

2 Foi posteriormente publicada, em conjunto com várias outras dos investigadores portugueses na revista Sinais de Cena, n. ${ }^{\circ}$ 12, Dezembro de 2009. 
público que - de forma mais acesa - avaliava as condições e as consequências de se aceitarem compromissos com o statu quo.

Luiz Francisco Rebello evoca o debate público, lastima alguma incompreensão por parte de um sector mais radical dos seus pares, e algumas das conversas privadas que a sua aceitação provocou e que não foram pacíficas.

Relembrando o ambicioso caderno de encargos que então elaborou (pp. 224 e 225), eram quatro as peças que propunha para uma primeira temporada: A Salvação do Mundo, de José Régio, A Mãe, de Witkiewicz, Platonov, de Tchékhov, e Fígados de Tigre, de Gomes de Amorim. Era, pois, uma pretensão que expunha desde logo um traço importante da sua política repertorial:

A planificação de cada temporada deveria prever a apresentação de quatro a cinco espectáculos teatrais, constituídos por duas peças clássicas, uma de autor português e outra de autor estrangeiro, e duas ou três de autores contemporâneos, igualmente nacionais e estrangeiros. (Rebello, 2004: 224)

É sabido que, em Novembro de 1971, logo a seguir à estreia do primeiro espectáculo da companhia - sobre o texto de Régio -, se verificou uma onda bem orquestrada de protestos, como refere nas suas memórias: «furiosa pateada na noite de estreia [...] críticas demolidoras e o desinteresse do público» (ibidem: 225). Mas a situação radicalizou-se logo a seguir: a peça prevista, a do dramaturgo polaco, incendiou as relações com a censura, que liminarmente a proibiu:

No que dizia respeito ao texto do dramaturgo polaco, entregue que fora a encenação de Artur Ramos - «depois de várias tergiversações e dois meses de ensaios» veio o veto da Comissão de Censura. As razões - imaginosas - invocadas pela censura mencionavam o facto de a peça «faz[er] a apologia da droga» (apesar de a Liga Portuguesa da Higiene Mental haver declarado que ela «manifestava uma atitude crítica ao uso de álcool e estupefacientes». (ibidem: 226)

Na carta que então Luiz Francisco Rebello endereçou ao presidente da câmara, declarava que «nunca poderia aceitar ser director de um teatro que fosse, de facto, dirigido pela Comissão de Censura» (ibidem: 227), denunciando ainda o «vício básico de que enferma[va] o exercício 
da actividade teatral entre nós, e que radica[va] na incapacidade da Comissão de Exame e Classificação para julgar espectáculos que transcendem a mediocridade» (ibidem: 227). Uma breve, mas certamente encorajadora, alfinetada num espectáculo de revista comentava o facto dizendo que «o Teatro São Luiz passara a chamar-se Teatro sem Luiz» (ibidem: 228).

Logo no ano seguinte, em 1972, novo incidente com a censura irá interferir na iniciativa do Instituto Alemão, em Lisboa: a de organizar um ciclo sobre «O teatro-documento alemão», para o qual Luiz Francisco Rebello fora convidado para proferir o discurso introdutório. ${ }^{3}$ As referências circunstanciadas que faz no seu livro de memórias convergem com o que se lê no volume dos Diários portugueses recentemente publicados pelo então director do Instituto Alemão Curt Meyer-Clason (2013). O programa era ambicioso e implicava não apenas conferências e apresentação de filmes, mas também a representação de fragmentos de obras de Rolf Hochhuth, Heinar Kipphardt, Tankred Dorst, Peter Weiss, entre outros. Artur Ramos encenaria ainda uma dramatização do interrogatório a que Brecht fora submetido, em 1947, perante a Comissão das Actividades Antiamericanas presididas pelo senador Joseph McCarthy. Todos acreditando que, como apesar de tudo parcialmente ocorreu, no espaço do Instituto poder-se-ia ter alguma liberdade de actuação. Mas o director do Instituto tinha a noção do risco que se corria quando sugeriu ao encenador Artur Ramos para não radicalizar excessivamente uma das cenas que se ensaiava:

A sua ideia [era] a de criar um palco secundário para cenas chocantes e procura[va] nos primeiros ensaios acentuar os papéis, caricaturar a figura do Papa n'O Vigário, dramatizar o interrogatório [...] Tenho de o dissuadir dessa ideia. Uma provocação deliberada podia atingir todos como um bumerangue, ou mesmo levar à minha extradição. (ibidem: 179)

Revelando também ter aprendido com a astúcia que crescera entre nós, Portugueses, Meyer-Clason rodeou-se, entretanto, de algum cuidado na divulgação da iniciativa, mesmo admitindo que o espaço do Instituto bem poderia ser tido como «extraterritorial»:

3 Em Combate por Um Teatro de Combate, Rebello refundiu e desenvolveu a palestra que aí tinha apresentado (pp. 111-31). 
O programa mensal, que é enviado a milhares de pessoas, universidades, associações de estudantes, clubes, grémios, imprensa, rádio e televisão ajusta-se ao monstro da censura: é parafrástico e lacónico e ao mesmo tempo transparente para atrair a curiosidade de destinatários sensíveis. Do título deste acontecimento só o iniciado pode deduzir o que o espera. As palestras têm títulos como: «Panorama histórico do teatro-documento», «Piscator e o teatro politico», «O teatro documento depois da segunda guerra mundial». (ibidem: 179-80)

Refere ainda Meyer-Clason que a peça Canto do Fantoche Lusitano, «por precaução, não pode figurar na bibliografia» do autor e cedo percebeu que em Portugal «quem escreve sobre Peter Weiss dá o nome através de uma paráfrase ou chama-lhe Pedro Branco» (ibidem).

Esta iniciativa do Instituto Alemão provou ser, sem dúvida alguma, uma iniciativa mobilizadora e acabou por ter um impacto muito importante. Mas continuavam as ameaças, os atropelos, a vontade de interromper, sem atender à argumentação sucessivamente invocada por Meyer-Clason na sua resposta à Comissão de Censura:

Parte desses filmes chegou tarde demais para poder ficar um mês na censura. [...] As peças não passaram pela Comissão de Censura [...] Trata-se de um ciclo pedagógico para participantes convidados [...] Não há encenações de peças completas, as representações de esboços ou fragmentos dramáticos servem apenas para ilustrar as conferências sobre o teatro alemão do pós-guerra. (ibidem: 181)

A certa altura, em conversa, o censor pareceu ficar menos intimidatório, e no final da conversa, aliviando o tom impositivo, deseja as melhoras ao director do Instituto - visivelmente engripado - e despede-se: «Desejo-lhe as melhoras, e espero conhecê-lo noutra ocasião. Mas o ciclo está definitivamente proibido» (ibidem).

Valeu na altura um jovem diplomata, o embaixador Dr. Vaz Pereira, que, respondendo ao apelo directo de Meyer-Clason, fez chegar ao Instituto Alemão uma autorização do Ministério dos Negócios Estrangeiros para se cumprir, afinal, o programa anunciado. Continuou o ciclo durante uma semana, mas algum cuidado ainda foi necessário, como recorda Meyer-Clason: 
Aos críticos (da nossa confiança política) dos matutinos e vespertinos pediu-se que só comentassem o evento depois de terminado o ciclo. [...] As últimas representações têm sala cheia. No dia 30 acabou tudo. [...] Os oito jornais, matutinos e vespertinos, da capital (com uma tiragem total de 300 mil exemplares) comentam detalhadamente o ciclo, os autores, as cenas apresentadas, a encenação, a representação, as conferências, os debates. Num gesto de oposição colectiva, os nomes de Brecht, Piscator, Peter Weiss, Hochhuth são referidos repetidamente; a foto de Brecht proscrito ocupa largo espaço em quase todos os suplementos. (ibidem: 185-6)

Mas é evidente que a imprensa afecta ao regime não deixou de acusar a iniciativa, invocando que «[a] cultura não faz esquecer» a «infâmia», como escreveu José Manuel Pintassilgo, padre e chefe de redaç̧ão do jornal Época. Alinhando inflamados parágrafos sobre a nobre missão de Portugal ao responder ao apelo do seu chefe (Salazar), mobilizando-se para defender o país em terras «ultramarinas», o autor do artigo apostrofava quem se tinha atrevido a trazer a Portugal «esse nome infame» de Peter Weiss (apud Meyer-Clason, 2013: 184-5).

E Luiz Francisco Rebello recorda também nas suas memórias a proibição da entrada em Portugal de Alfonso Sastre e a referência pública a Peter Weiss (cf. Rebello, 2004: 231).

Já antes, em 1969, quando decorria em Aveiro o II Congresso Republicano, Luiz Francisco Rebello apresentara uma comunicação sobre a «Situação do Teatro em Portugal», justificando a pertinência de chamar a atenção sobre uma arte que, na sua opinião, era res publica, ou seja «a transposição de uma vivência ou de uma mitologia colectivas» e o palco «o lugar onde ressoam, serenas ou agitadas, as pulsações do coração da cidade» (1977: 9).

Insurgia-se Luiz Francisco Rebello não apenas pela questão política intolerável da censura prévia em si própria, mas por todas as consequências que daí decorriam: não apenas a proibição de peças e espectáculos, mas também a consequência de uma crescente incapacidade dramatúrgica de autores, que não tinham, por essa razão, acesso à experimentação dos seus textos em palco. Daí resultava, como seria inevitável, um divórcio que se criava entre a realidade vivida e a criação teatral, como argumentou:

Enquanto os dramaturgos portugueses não puderem assumir, nas suas criações, a realidade nacional e dar testemunho verdadeiro do seu tempo, 
dos seus sonhos, das suas derrotas, das suas frustrações e das suas esperanças, como poderá estabelecer-se esse diálogo entre o homem da sala e o homem da cena, sem o qual o teatro não cumpre a sua missão? (Rebello, 1977: 19-20)

Nas suas memórias Luiz Francisco Rebello dá-nos, de facto, uma circunstanciada descrição do que ao longo dos anos 60 foi a permanente e insidiosa actuação da censura: não apenas a perseguição movida ao Centro Português do Instituto Internacional do Teatro (pp. 179 e ss.), mas também ao Grande Prémio de Teatro que a Sociedade Portuguesa de Escritores atribuiu a partir de 1962. O texto premiado, de Sttau Monteiro, em 1962 - Felizmente Há Luar -, foi proibido de ser representado pelas «suas evidentes tendências políticas [e] nítidos fins especulativos, como é costume do seu autor» (Rebello, 2004: 183).

O mesmo ocorreu com a peça vencedora da segunda edição do Prémio em 1964ㄴ, em que o júri foi constituído por Paulo Quintela, Eduardo Scarlatti, Urbano Tavares Rodrigues, Rogério Paulo e José Régio. A peça premiada foi Condenados à Vida, de Luiz Francisco Rebello. Nestas circunstâncias - de uma obstinada asfixia-, não admira que o Prémio tenha acabado por ser descontinuado. A justificação dada por um dos censores para vetar a representação desta peça foi: «excedia, em intenção político-social de muitas das suas passagens, o que se podia e costumava ser autorizado» (apud Rebello, 2004: 186).

Não diminuíram as interferências da censura-até 1974-, assim como não diminuiu a vontade de Luiz Francisco Rebello continuar a traduzir outros e a inventar o seu próprio universo teatral, que, como observou correctamente António Braz Teixeira (na introdução ao $2 .^{\circ}$ volume de Todo o Teatro, de Luiz Francisco Rebello, em 2006), integra e cruza duas linhas fundamentais: «uma predominante meditação sobre a condição e destino do homem numa perspectiva de cariz marcadamente existencial e centrada no universo familiar e [...] preocupações de ordem político-social», mantendo ambas, como acrescenta, «uma atitude ou um ponto de vista decididamente moral» (2006: 9-10). Avança ainda Braz Teixeira, nesse «Prefácio Breve e Talvez Inútil», o que ele considera ser a avaliação geral unânime que intelectuais dos mais diversos quadrantes - estéticos e políticos - fazem da obra de Rebello:

4 O Prémio de Teatro instituído pela Sociedade Portuguesa de Escritores em conjunto com o da Poesia alternava com o da Novelística e do Ensaio. 
[...] a sólida modernidade do teatro de Luiz Francisco Rebello, a sobriedade e a naturalidade da linguagem das suas peças, a densidade e a verdade humana e psicológica das suas personagens, o seu profundo sentido teatral e a sua habilidade na condução da acção dramática, bem como a lucidez e a coragem de denunciar as cobardias, falsidades e traições que hoje e em qualquer tempo, o ser humano comete, deixando-nos, contudo, vislumbrar uma réstia de esperança na possibilidade de uma regeneração moral [...]. (Teixeira, 2006: 15)

Não é este, obviamente, o momento para proceder a uma análise das características do seu universo dramático, ou para sublinhar a amplitude das temáticas que foi podendo abordar já depois de abolida a censura, mas gostaria de tomar uma das suas peças como o outro modo que ele quis - e soube - usar para falar das condições de asfixia política que a censura impunha antes de 1974.

Foi no contexto de uma iniciativa da Fundação Calouste Gulbenkian em 1982, quando se preparava uma exposição evocativa da arte portuguesa na década de 1940, que Carlos Wallenstein sugeriu a Luiz Francisco Rebello a escrita de uma peça que funcionasse como uma espécie de crónica sobre a vida portuguesa nesse período. Para um historiador que conhecia bem o teatro que então se fazia e o contexto político que marcou toda essa década, não seria difícil. Além do mais, como lembra na sua autobiografia, era nessa década um jovem entrado nos seus vinte anos, pelo que essa viagem no tempo e nos afectos era um aliciamento irresistível.

Todavia, evitando a solução fácil da simples colagem das coisas que então se faziam em palco, Luiz Francisco Rebello usou uma mais ampla panóplia de possibilidades técnicas e artísticas: misturou vivência pessoal e história de outros, texto a dizer e soluções audiovisuais, notícias dos meios de comunicação social e ficção, compondo um imenso fresco social e político em que não faltou a recordação de alguns dos espectáculos, sobretudo de teatro de revista, que então tinham sido grandes êxitos. Houve, porém, nessa altura um pequeno exagero por parte do encenadorCarlos Avilez-, que, entusiasticamente, terá, na opinião de Luiz Francisco Rebello, exagerado a vertente festiva com um excessivo uso desse teatro mais vistoso, o que diminuía a crítica à ditadura que o espectáculo também visava mostrar. Um maior equilíbrio e uma mais apurada visão de como era a vida nessa altura marcarão a reposição do espectáculo em Cascais em 1996 ainda sob a direcção de Avilez (e essa foi a versão que vi). 
O que me parece mais interessante nesta sua peça é a competência com que soube entretecer cenas no espaço privado e na rua, ou no emprego e em lugares de diversão, mas sobretudo a segurança com que desenha um microcosmo credível ao mesmo tempo que se sinalizam pontos fundamentais de caracterização de uma época. Como espectadora, recordo dois momentos de uma força teatral extraordinária: a cena em que se recordava um acontecimento que tinha efectivamente ocorrido num cinema em Lisboa, no final da projecção do filme Casablanca, quando o público depois da última cena se levantou entusiasmado e cantou a Marselhesa. Outro momento importante foi a sexta sequência, quando, depois da notícia da derrota de Hitler, se passa à alegria na rua, mas que rapidamente fica ensombrada com novas proibições e recrudescimento da repressão em Portugal. No silêncio total, começa em surdina uma das canções heróicas de Lopes-Graça sobre texto de José Gomes Ferreira: Acordai. Foi um momento de uma intensa vibração, que dava a medida exacta de como o teatro é «lugar de assombração», podendo, afinal, reencenar a vida.

Estas são também as linhas com que Luiz Francisco Rebello coseu, na sua escrita ensaística, uma História do teatro, que não deixa de ser também um capítulo importante da História que ele ajudou a fazer. 


\section{REFERÊNCIAS BIBLIOGRÁFICAS}

MEYER-Clason, Curt (2013), Diários Portugueses (1969-1976), pref. e notas de João Barrento, Lisboa, Sistema Solar (Documenta).

RE BELLO, Luiz Francisco (1977), Combate por Um Teatro de Combate, Lisboa, Seara Nova.

-- (2004), O Passado na Minha Frente: Memórias, Lisboa, Parceria A. M. Pereira.

-- (2006), «É verdade. Mas ... Duas proposições sobre a censura», Sinais de Cena, n. ${ }^{\circ}$ 7, Junho de 2007, pp. 47-52.

-- (2009), «Vozes silenciadas, Vidas proibidas: A censura e o teatro», Sinais de Cena, n. ${ }^{\circ}$ 12, Dezembro, pp. 9-10.

TEIXeIRA, António Braz (2006), «Prefácio Breve e Talvez Inútil», in REBELlo, Luiz Francisco, Todo o Teatro, Vol. II, Lisboa, Imprensa Nacional-Casa da Moeda, Biblioteca de Autores Portugueses.

\section{MARIA HELENA SERÔDIO}

Maria Helena Serôdio é professora catedrática aposentada e investigadora do Centro de Estudos de Teatro da Faculdade de Letras da Universidade de Lisboa. Publicou diversos artigos, colaborando com revistas, enciclopédias e outras publicações nacionais e internacionais. É autora de, entre outros títulos, Questionar apaixonadamente: O teatro na vida de Luis Miguel Cintra (Cotovia, 2001), Joaquim Benite Desafiou Próspero... e Inscreveu o Mundo no Seu Teatro (Companhia de Teatro de Almada, 2013) e Financiar o Teatro em Portugal: A actuação da Fundação Calouste Gulbenkian (1959-1999) (Fundação Calouste Gulbenkian/Bond Books, 2013). É co-fundadora e presidente honorária da Associação Portuguesa de Críticos de Teatro e Honorary Secretary General da Associação Internacional de Críticos de Teatro (AICT). 